\title{
Playing hard: Young men's experiences of drinking in inner-city Melbourne
}

Dean A. Murphy

National Drug Research Institute, Curtin University, Australia

Centre for Social Research in Health, UNSW Australia

Corresponding author:

National Drug Research Institute (Melbourne), Curtin University, Suite 6, 19-35, Gertrude Street, Fitzroy, Victoria, 3065, Australia. Email: dean.murphy@curtin.edu.au

James C. Wilson

National Drug Research Institute, Curtin University, Australia

\section{David Moore}

National Drug Research Institute, Curtin University, Australia

\begin{abstract}
In recent years, the concept of 'calculated hedonism' has dominated sociological understandings of young people's drinking practices. However, while contributing some important insights, this conceptualisation has not sufficiently considered the affective and embodied aspects of alcohol consumption. Our analysis explores the meanings and understandings of alcohol consumption among male participants in an eighteen-month study of young adults living in inner-city Melbourne. Data were collected via in-depth, semi-structured interviews and participant observation during drinking events. We draw on Roger Caillois' notion of 'play' to analyse sessional drinking among these men. The four categories of play identified by Callois competition, chance, simulation and vertigo - were all present in the accounts of these men's drinking practices. This analysis offers a way of conceptualising men's alcohol consumption in more nuanced ways that acknowledge the affective and embodied aspects of drinking as part of pleasure-seeking.
\end{abstract}

\section{Key words}

Alcohol, emotionality, calculated hedonism, play, ethnography, Australia 


\section{Introduction}

Over the last two decades, the concept of 'calculated hedonism' has dominated sociological understandings of young people's drinking and other drug-use practices. Although such analyses have provided extensive evidence for the bounded and contexualised nature of alcohol consumption, the affective and embodied experience of drinking has received less attention. In this article, we explore these experiences of alcohol consumption among social networks of young men living in inner-city Melbourne by drawing on Roger Caillois' (2001 [1961]) concept of 'play'. By analysing alcohol consumption as part of play, we incorporate calculated hedonism's focus on the boundedness imposed by time and space, while also focusing on drinking as part of an assemblage or event.

\section{Background}

Influenced by the work of Featherstone $(1982 ; 2007)$, several authors have described the way young people manage pleasure around alcohol (and other drug) consumption as ‘calculated hedonism' (Brain 2000; Crocket 2014; Fry 2011; Griffin et al. 2009; Measham 2004a; 2004b; 2006; Parker and Williams 2003; Szmigin et al. 2008). The notion of 'controlled loss of control' (Measham 2002; Measham and Brain 2005), which is central to calculated hedonism, disrupts the binary of rationality and emotion (Crocket 2014), and echoes other sociological and feminist problematisations of this distinction (Barbalet, 2001; Mumby \& Putnam,1992; Turner, 2009). In this conceptualisation, pleasure seeking remains confined by time, space and social situation (Measham 2004a; 2004b; Szmigin et al. 2008) and, in this sense, is neither irrational nor separate from cognitive processes. Sociological analysts of calculated hedonism have also argued that it reflects the turn to consumption as a way of performing pleasure and identity (Brain 2000; Crocket 2014; Featherstone 1982, 2007). Measham and Brain's (2005) work, in particular, traces how the emergence of night-time economies -- urban zones focused on alcohol consumption and other entertainment -- has contributed to a new 'culture of intoxication'. However, as Crocket (2014) notes, discourses of neoliberalism that responsibilise individuals for problems such as excessive drinking have also become prevalent. These discourses have also influenced analyses of drinking, including the calculated hedonism approach, which position individuals as responsible for managing their own pleasures and risks. 
Calculated hedonism is a useful theoretical tool for thinking about the 'bounded' nature of drinking and other drug-taking practices, and politically it has been a useful counterpoint to uncritical media and policy discourses of 'binge drinking' and uncontrolled consumption of other drugs. However, the contextualised experience of embodied pleasure - as an explanation for alcohol and other drug use - has received less attention (Duff, 2008; Keane, 2009). Research on calculated hedonism has also tended to ignore gender in its focus on 'young people' as an undifferentiated group - a notable exception being Measham's (2002) earlier work on the performance of gender through drug use. Finally, the literature on calculated hedonism focuses on alcohol consumption rather than conceptualising alcohol as one element in the arrangement or assemblage of an event.

\section{Theoretical framework}

A potentially useful contribution to theorising alcohol-related emotions, pleasure, embodiment and affect comes from recent work in cultural geography (Jayne et al., 2012; Jayne et al., 2006; Jayne and Valentine, 2016; Jayne et al., 2008, 2010; Roberts, 2015; Stevens, 2007). Jayne and Valentine (2016) suggest that approaching these aspects of drinking through the prism of 'play' may contribute to better understandings of alcohol-related violence and disorder. The concept of 'play' informing these analyses emerges from sociology (Caillois, 2001 [1961]; Giddens, 1964) and from its earlier treatment by cultural theorist Johan Huizinga (1949). Play has several features that distinguish it from other activities. First, it is voluntary, and is positioned "quite consciously outside "ordinary" life as being "not serious"' (Huizinga, 1949: 32). Second, play is self-rewarding, meaning it is not associated with material benefits (Giddens, 1964; Huizinga, 1949). Play is also bounded by space and time in the sense that it takes place in a defined temporary world governed by rules and is accompanied by an awareness of a second reality (or sphere of 'make believe') (Caillois, 2001 [1961]: 9-10; Huizinga, 1949).

Caillois (2001 [1961]) theorised four different forms of play: competition, chance, simulation and vertigo. He argued that modern cultures were distinguished primarily by games involving a tension between two of these elements - competition and chance. Jayne and Valentine (2016) argue that alcohol can be understood 
as a 'technology of the self' (Foucault, 1988) that enables playful activities (see also Jayne et al., 2010). They make several suggestions for thinking about drinking and drunkenness as play, and specifically draw on the forms of play described by Caillois. They argue that drinking and drunkenness are ways in which people compete with one another, for example through drinking games (including speed and quantity of consumption), contests to get served and 'picking up' (i.e. gaining sexual partners). However, competition is not only about winning against others, but involves the establishment of individual and social limits.

Second, drinking practices produce openness to chance, which refers to forces other than rationality, effort, experience or skill. Previous research has highlighted some of these elements of chance in relation to alcohol, drinking and drunkenness. These include atmosphere (e.g. sounds, smells), physical layout of venues, proximity to other people, interactions with friends and strangers, tiredness, type of drink consumed, hunger, and mood (Jayne et al., 2010; Jayne and Valentine, 2016). As Jayne et al. (2010) argued, the 'effects of alcohol along with interaction between people and their surroundings come together to produce “drunkenness"'. Chance elements are particularly valued because 'alcohol consumption is often underpinned by habitual mobilities through commercial venues/public spaces' (Jayne and Valentine, 2016: 73).

The play form of simulation is the fabrication of a different character or situation (Jayne and Valentine, 2016; Stevens, 2007). An important aspect of simulation (or engagement with otherness) with regards to alcohol is the effect of space and place on drunkenness. Simulation was historically associated with assuming different characters, for example, through adopting a disguise or mask during periods of carnival. However, this pantomime does not necessarily mean that one's identity is truly concealed but rather that there is an understanding among participants that concealment gives permission for practices to emerge that would not be possible in everyday life (Caillois, 2001 [1961]). The social function of simulation is satire, which is a response to the dignity or deference that exists in other parts of one's life (Caillois, 2001 [1961] (see also Goffman, 1959). There is also some similarity with the 'sneaky thrill' reported by people who participate in petty crime such as shoplifting or vandalism, in which the thrill is created by the interplay between being 'seduced to deviance' and maintaining 'normal appearances' (Katz, 1988: 53). 
The final form of play, vertigo, describes practices that escape normal experience and self-control, including 'bodily actions which generate intoxicating, physical sensations of instability and distorted perception' (Stevens, 2007: 41; Jayne and Valentine, 2016: 75). Vertigo, which Caillois also refers to as ecstasy, frenzy, possession, stupor and paroxysm, is a temporary aberration. Vertiginous effects can be created through lights, music, speed, fright, and other 'forms of fascination' that are designed to disorient or confuse (Caillois, 2001 [1961]: 134). The example given by Caillois was funfair (or amusement park) rides that temporarily alter perception. The design of drinking venues such as bars and nightclubs can also be seen as deliberate attempts to alter perception or disorient through sound, light, reflections and distortions of shapes and space. Managing the psychoactive effects of alcohol and other drugs is also a form of vertiginous play, especially the bodily practices associated with achieving intoxicated self-control (Zajdow and MacLean, 2014).

The concept of play, and the forms therein, corresponds to some extent with one of the eight recreational drinking styles among young men described by Harnett at al. (2000) as 'having a laugh'. In this drinking style, the consumption of alcohol was bound up with other elements such as being in a venue, mixing with male friends, achieving a high, and having a good night - all of which were part of the event. The point we emphasise here is that drinking is merely one element in the ongoing production of a night out, and through which myriad possibilities are opened up. This description also aligns with Jayne and Valentine's claim that 'playing has more to do with becoming rather than being' (2014: 76). The notion of play allows for a more nuanced analysis of young men's experiences of alcohol consumption, and also represents an effort on our part to focus on the affective and embodied aspects of pleasure and to explore the meanings and understandings that young men produce during drinking events. 


\section{Methods}

\section{Data collection and analysis}

The article draws on data collected by the second author (JW) as part of an ethnography of young adult drinking practices in Melbourne. During eighteen months of fieldwork in 2012-13, he socialised with participants two-five times per week, attending approximately 200 drinking events at over 120 public and private venues including pubs, nightclubs, restaurants, public areas, sports matches, wineries, music festivals, community events, and private homes and parties. In order to build familiarity, rapport and a legitimate social role amongst the network of participants, JW developed intensive relationships with four 'gatekeepers' (Payne and Payne, 2004) and they mediated access to other potential participants. Maintaining a legitimate social role in this context often meant the researcher's visible alcohol use functioned as a crucial tool in achieving rapport and access to local perspectives and practices (Palmer and Thompson, 2010). The 'professional dilemma' of consuming alcohol while maintaining a research role (Palmer and Thompson, 2010) was continually re-negotiated throughout fieldwork by checking recollections and interpretations with participants after nights out and using hand-held recording devices during drinking events to ensure the accuracy and richness of the data. After each drinking event, observations and conversations were recorded in field notes. The study received ethics approval from Curtin University's Human Research Ethics Committee (HR107/2012).

The field notes and interview transcripts were entered into the NVivo software program. The first author coded the materials using an inductive approach (Boyatzis, 1998) as well as drawing on themes in the existing literature on alcohol consumption. Conceptual and descriptive codes were developed after reading a small number of interviews and field notes and discussions with JW. These codes were then tested on the remaining material, and supplementary codes were added in a systematic and reflexive way across the data set. In particular, we analysed the data in relation to the forms of play described by Caillois (2001 [1961]; Jayne and Valentine, 2016). 


\section{Participants}

JW's relationships with the four 'gatekeepers' or core participants (three male, one female) mediated access to a further 56 individuals ( $\mathrm{N}=60,32$ male, 28 female), all of whom participated in at least two observed drinking events. The analysis we undertake here focuses on data derived from the 32 male participants. These men were from Anglo, other European and South Asian backgrounds, and, at the time of fieldwork, their average age was 25.81 years (range 23-31). The majority were heterosexual and lived in Melbourne's inner suburbs in shared rental properties (two or more persons), while two rented alone and one lived in his family home. Most participants were tertiary educated, employed full-time in professional or hospitality positions, and were financially independent. Typically, these men consumed alcohol, often heavily, on a weekly basis, which places them in the $25.1 \%$ of Australian males aged 20-29 years who drink more than four standard drinks on a single occasion at least once a week (Australian Institute of Health and Welfare 2014: Table S4.3). Some participants also reported consumption of other drugs (mainly cannabis and ecstasy). In addition, five of these men participated in in-depth interviews exploring themes of drinking preferences, patterns, practices and histories, as well as alcohol effects, other drug use and narratives relating to recent nights out. This paper analyses data derived from these interviews and ethnographic data involving the five interview participants and the other 27 male participants in the study $(n=32)$.

\section{Play}

The accounts of drinking offered by the participants - in which they described organising their alcohol consumption around other commitments, primarily work, health and financial resources - echoed the forms of 'calculated hedonism' or 'controlled loss of control' described in the existing literature (Katainen and Rolando, 2014; Measham and Brain, 2005; Moore, 2010; Szmigin et al., 2008). However, analysing sessional drinking through the frame of 'calculated hedonism' leaves unexamined important aspects such as affect, embodiment and the processual nature of alcohol consumption. We therefore analyse the participants' accounts of drinking and drinking-related events, and in particular the elements of 'play' featured in these accounts. This exploration is an important supplement to studies of calculated hedonism, not least because it 
provides a more detailed account of the pleasures of alcohol consumption and the context in which it takes place.

\section{Competition}

We have already noted that the notion of play corresponds to some extent with one of Harnett et al.'s (2000) 'recreational' styles of male drinking - that of 'having a laugh'-with its focus on embodied pleasure. The men in our study often engaged in drinking sessions in which being 'funny' was an important element in creating the right atmosphere. Being funny also involved a degree of competition between men. They described these experiences as a way of bonding with 'mates' through adventures that involved successes or humiliations among members of the group audience. An important part of these events was, as Aiden describes, the production of stories that could be recounted later:

Like for me I always want like a night to have one funny story. Like, one of my mates like gets rejected or someone picks up a girl or someone doesn't get let in to [an event] or someone drops a drink and ... like that's what I want.

While the pursuit of sexual partners was important in the men's accounts, this form of play was not solely defined by 'picking up', as noted in Aiden's comment. To emphasise this point, Aiden added that he would 'almost rather, like, have a bad experience with a girl that's funny that I can share with my mates, than take a girl home.' This comment emphasises that rejection could also be turned into playful competition in the form of a 'funny story' for the consumption of male friends.

As Jayne and Valentine (2016) note, play occurs in a public setting, which enables both 'showing off' and being judged by others (see also Stevens 2007). The field notes provide numerous instances of competitive play at public drinking events, especially in relation to attempted 'pick-ups'. The following field note excerpt describes an incident in a bar:

Will was waving his arms around in the air, attempting to dance. A group of short girls walked past to get to the bar and caught the eye of our group [offour men], and we all pushed Will in that 
direction given their comparable heights [between the 'short girls' and Will, who was the shortest of the men], and interestingly, they seemed fairly keen.

This excerpt captures the playful engagement between the four men in the group ('we all pushed Will in that direction') and between this group and others in the venue - in this case the 'group of short girls'. As suggested by the previous example, play does not necessarily imply competing against each other as a more limited definition might suggest, but rather that being 'funny' was a form of competitive play in itself. In the described incident, for example, although the field notes record that the women seemed 'fairly keen' on Will, the enjoyment of the group would not have been diminished if the women had shown little interest.

Despite the emphasis on 'fun', competition could also take a more open form in which success in gaining a sexual partner was as important as the stories that might emerge from its pursuit. For example, Jobe recounted occasions where success was important: 'you set yourself a goal, you set it and you achieve it'. This form of competition had a different effect on the group. While 'being funny' strengthened the cohesion of the group, the determined pursuit of sexual partners could also create a different effect as suggested by the following field note:

However, half-way through the first beer, about 20 minutes in, the focus switched from catching up to talking to girls. Jobe's housemate almost immediately approached the nearest group of girls and then another, and then another. This was about 10pm or just after. In fact I asked Jobe how they managed to do this so soon after entering. He actually replied 'Yeah it's a bit stupid, it's only 10.15. We're not going to pick up until at least 11'.

By drawing on Huizinga's (1949) theorisation of play, we offer one possible reading of this account: Jobe and his housemate threatened the atmosphere of playfulness and the harmony of the group. Their actions were incommensurate with the notion of play as 'disinterested' (Huizinga, 1949: 27). For Huizinga, play is the opposite of seriousness, although he also notes that the contrast between the two is always fluid and open to redefinition. In addition to illustrating how competition could cause disruption within the group, this account provides an insight into the scripting of a night out and in particular the optimum time for 'picking 
up', which was influenced by time spent in the venue and also possibly by levels of intoxication. These scripts provide the unwritten rules of play.

Alcohol played an important, if precarious, role in attempts to pick up women. According to the accounts of these men, alcohol could potentially facilitate a sexual encounter but, equally, alcohol could also prevent such an encounter. As Luke reflected:

If you go out sober and try and pick up a girl that's drunk, you're suddenly, you know, the villain, and they're the victim. Because you're trying to pick up someone that's more vulnerable than you ... if you're not very drunk, you're going to look like that sad person trying to pick up ... you should almost become more drunk, there's like a balancing act, dude.

These accounts suggest the importance of achieving the right mood. Alcohol contributes to attaining the affective state necessary for an enjoyable experience, as do other elements such as the design of drinking venues and interactions with others. In this way, drinking 'enables playful engagements in urban public spaces and commercial venues as people reach inside/outside themselves in order to understand individual/social limits' (Jayne and Valentine, 2016: 73). However, playful engagement or competition could also be considered somewhat precarious, and it is therefore useful to reflect briefly on how limits could be exceeded.

\section{Disrupting play}

Jayne and Valentine (2016) also outline how the fragile basis of play could be disrupted through 'cheating'. This disruption is what Huizinga referred to as 'ordinary life' reasserting itself, which, he argued, could come from without in the form of an interruption or offence against the rules, or alternatively from within through a collapse of the play spirit, which he described as a 'disenchantment' or 'sobering' (Huizinga, 1949: 40). For Huizinga, play contains the consciousness of 'only pretending' (1949: 41) and for this reason play is susceptible to a destabilisation of the mood in which participants are collectively engaged in producing. 
The men's accounts suggested that the greatest threat to mood was violence, and they all took measures to avoid its disruption of their play. The men who had experienced violence in drinking situations made it clear that they were the target of other men's aggression. Thus, despite their own preference for avoiding violence, these men were aware of its ever-present possibility. The following field note captures this threat to play:

Jobe talked about Ballarat as being a completely different place to go out (he had just been for a boys' weekend for one of his mate's birthdays.) Either just good-looking young girls or 'cougars' [a term referring to older women seeking sex with younger men] and nothing in between, and the competition for the pretty girls was just too strong, both in numbers and also in personality and physique. Jobe said he spent the entire time in anticipation that something was just going to kick off', although thankfully it never eventuated.

The threat of violence ('anticipation that something was just going to "kick off"') demonstrated the fragility of playfulness, and the way in which it could be easily destroyed.

\section{Chance}

The second category of play is 'chance', in which participants open themselves up to the unexpected. Huizinga (1949: 29) referred to this element as tension, which is necessary in play, and which players seek to resolve, thereby giving play its competitive dimension. For the men in this study, chance was enabled though attendance at commercial venues such as bars and clubs. These environments offered numerous possibilities due to the presence of other people with whom they could interact. As Jobe said, 'we like to be funny, have a good time with everyone, you know?' He also recounted how interactions with other patrons - other men, as well as women - in addition to music and other elements, added to a general atmosphere of playfulness:

Just talk to everyone we can, you know, girls ... you know, some, we always get talked to by dudes as well. It's pretty funny. Umm ... not gay dudes because that's weird. Just to be ... a disclaimer on that one. But umm ... no, no, it's just one of those things, you know, it's ... you enjoy, really enjoy it to go out and ... mingle and loud music and things like that. 
Although Jobe actively excludes 'gay dudes' from his category of acceptable others, an important aspect of these accounts is the open-endedness and spontaneity of a night out. This included the temporal parameters of the night and the possibility of different outcomes, including, for example, going home with someone or waking up to discover that 'you've just rung all your ex-girlfriends' (Jobe).

Although many of the men in the study described having close female friends, most of these men's drinking stories - especially those involving evenings defined as pleasurable - excluded women as participants. As Jobe recounted in the following exchange, the exclusion of female friends opened up more possibilities and maximised the pleasurable 'tension':

Interviewer: Do you usually go out with guys mainly?

Jobe: Yeah, I just go out with my mates all the time. We always go to meet girls. It's harder when you bring girls with you.

Interviewer: Is it?

Jobe: Of course!

Interviewer: Why?

Jobe: Because then they think you're couples.

Drinking or 'going out' was usually associated with the possibility of picking up or meeting women. Being in a group of men signalled to potential sex partners that the men were sexually available. As Jobe described, a mixed gender group could suggest that they were couples 'and then you have to do some explaining' in order to make your availability clear to potential sexual partners. This aspect of chance (i.e. sexual success) could also be enhanced by choosing particular venues over others, for example, by avoiding venues with mostly male patrons.

Drinking was a crucial part of these nights out, but it was not only the effects of intoxication but rather the experience of the night as a whole that was prized by participants. Being too drunk could negatively affect a 
night out through becoming ill or being refused entry to a venue; it could also undermine one's chances of picking up. A degree of vigilance was therefore required to manage the effects of alcohol without being too intoxicated, as suggested in the following field note:

When Wade was asked if he wanted a drink, about 8pm and half way through his dinner, he responded with, 'I'll have one about 20 past. Can't be too drunk man.' His shifty look at me insinuated it would diminish his ability to talk to girls. He had discussed his theory before - that one cannot be too drunk when trying to pick-up girls both because it's difficult to concentrate, string words together, and you could say something wrong or embarrassing; but also because girls are turned off by guys who are clearly intoxicated.

Another theme in the accounts of participants was that a good night out should not be too carefully planned, or rather should not appear to be planned. Spontaneity or flow was highly valued and drinking was invoked as an important aspect of this movement through an evening. As Jobe explained:

Oh, it's more like going out and socialising. I sort of don't always tend to go out and have a big night. But then, sort of, I don't know, one of my mates might just hit turbo, then I'm like 'all right, I'm in'. And then it just goes crazy and you end up at 4am doing jagerbombs [a drink made from Jägermeister, a German herbal digestif (ABV 35\%), and an energy drink, typically Red Bull].

Elsewhere Jobe described this as the 'snowball effect - once you start going down that hill, you don't stop until, you know, you're in bed just munted [extremely drunk]'.

However, despite the emphasis on spontaneous flow, a great deal of forethought often preceded a night out, in terms of timing, venue, dress and group composition. The venues themselves also could facilitate a playful atmosphere through design, lighting and music. The importance of venue design in shaping the experiences of, and interactions between, male and female patrons has been noted in previous research (Lindsay, 2006; Waitt et al., 2011). In addition, the field notes provide examples of how the achievement of the right atmosphere was aided by friendly security and bar staff or by particular entry policies that prevented too great an imbalance between male and female patrons. This attention to venue characteristics, and the importance of their design and entry policies, were, however, usually bracketed out and excluded from men's 
accounts of a pleasurable night out. The necessity of excluding these quite intricate preparations underscores the importance of making particular alcohol or other drug-related events seem unscripted or unplanned.

\section{Simulation}

These young men articulated a desire to balance work and play, a balance captured by the phrase "work hard, play hard' that was invoked several times in the interviews and field notes. In terms of the analysis we undertake here, it is important to note that these men used the term 'play' to describe alcohol-related activities and positioned intense play as the counterweight to the demands of work. In Caillois' (2001 [1961]) terms, simulation offers an opportunity to restore the equilibrium (or control, agency) which in this study was undermined by the demands of work, in particular the observance of workplace hierarchies. Participants described going out and drinking as a way of creating or restoring a balance between leisure and the responsibilities of work life. As Aiden noted:

Still want to feel 25, yeah. Still want to like, you know, wear my kicks [shoes] and talk shit and fucking, you know, whatever. So yeah, like I reckon probably, it's funny like, definitely I'd probably be the most immature out of all my mates. Yeah, but like when it comes to work, like I've definitely got the most full-on job. So, I reckon that's definitely part of it, sort of compensating.

For Aiden, work not only delineated the times during which (heavy) alcohol consumption could take place, but also enabled drinking itself through these narratives on the necessity of balancing ('compensating' for) the intensity of work through playful leisure.

For young men in professional work environments, drinking with 'mates' could also symbolically restore a masculinity sometimes threatened by their role as junior staff in predominantly male workplaces. As Aiden recounted, drinks at work were governed by particular rules, with senior colleagues taking the lead in conversations and paying for drinks. These rules demanded deference to workplace hierarchy with junior colleagues required to undertake a form of 'emotion work' (Hochschild, 1979) by assuming attentive and subordinate roles: 
That's their social life. And they love, you know, having a 25-year-old kid listen to their fucking stories, and you know, you put up with it. And you know, they buy you the beers. It's almost like the arrangement: you listen to me, I'll buy you some drinks, and you know, we'll get along, and that will help your career. (Aiden)

For these young men, Friday evenings represented a transition from work to play and a shift from the selfcontrol and moderation of the working week to the pleasure and excess of the weekend:

But then on Friday it's just, you know. I work a pretty hard job. So you know it's quite nice just to go out, unwind, let loose, talk to girls, you know, have a bit of fun. I guess that's what it's all about you know, it's just getting away from the ... getting away from working for the man! (Jobe)

This transition often included drinks with the work colleagues, followed by meeting friends at other venues for further drinks. The transition also included a move from a drinking environment governed by certain rules about attire, respect and topics of conversation, to one that was much more open in terms of pleasures and possibilities. In this way, it also fits Caillois' notion of simulation by providing an opportunity to restore equilibrium through a symbolic reversal of roles.

\section{Vertigo}

Particularly valued in the men's accounts of drinking were the 'changes of direction' (Harrison et al., 2011) or 'enhanced state' (Keane, 2009) offered by alcohol. The final category of play, vertigo, refers to practices that facilitate escape from normal experience and distort perception (Caillois, 2001 [1961]; Stevens, 2007). Managing the psychoactive effects of alcohol and other drugs is a form of vertiginous play, especially the practices associated with achieving an intoxicated self-control - that is, achieving a state of being 'tipsy' but not too drunk (Zajdow and MacLean, 2014). Some of the men in the study recounted how they attempted to achieve the right balance, usually based on bodily experience. Aiden described his pursuit of a specific level of intoxication that he knew, from previous experience, was the right 'level' to maximise enjoyment:

Like, if I get to that point where I've had a few drinks and I feel pretty tipsy, like, that's better. And I'm pretty good now at like staying at that level, where I really can feel whether or not I've had a 
little bit too much. Like I feel like now, you know, I have enough amount of alcohol just to sort of keep me at a level which I'm having fun, I'm excited, and a little bit tipsy, and just sort of just sustain that for like as long as I can, then I have a much better night than like, going hard and getting really drunk and then like being in bed at 11 because Ifeel sick.

As suggested in Aiden's account, there is always a risk that 'going hard' could result in the evening ending prematurely. Jobe similarly described the desire to achieve a certain 'level', which, in addition to bodily experience, was maintained through comparison to other people: 'I sort of can realise when I'm at that level. So I sort of slow down a little bit. But ... some nights, you just let rip [drink heavily]'. Thus pleasure could be maximised by achieving a certain 'level' but, on some occasions, that level might be exceeded intentionally ('you just let rip'), which could also be associated with regret or shame. As Luke recounted: 'I've definitely drunk way too much in the aim to get a woman, to pick up some sort of girl. And I've definitely done some silly things, some silly, silly things in clubs and bars trying to meet that goal'. However, according to Jobe, doing things while drunk did not lessen enjoyment of the occasion because awareness of these actions was sometimes deferred:

But, I mean, probably a bad thing is when you look at your phone the next day and you've just rung all your ex-girlfriends at like 4am, and you're like, 'Oh man, I'm such a disgrace'. That probably is a bad night. But that definitely happens at the end of the night, and then you don't remember about it so technically it doesn't dampen the night until the next day.

This story from Jobe emphasises again how the pleasure of a night out could be extended beyond the event itself to stories that could be recounted later. As his quotation suggests, this was often facilitated by the technology of the mobile phone. However, in contrast to the young women described in other studies (e.g. Brown and Gregg, 2012), there were few examples of the men taking photographs or using social media sites to document their evenings of play.

Overall, men described alcohol as creating a degree of disorientation and this effect was a pleasurable aspect of drinking. They commonly described this effect as being 'loose': 'Like, you know, having a few drinks, you just, you loosen up a bit. ... . But, I don't know, when everyone's just had a couple of drinks, it's just, 
everyone's a bit funnier'. The altered perceptions achieved through alcohol use were an important part of socialising. Not only did alcohol contribute to a different, temporary self; it also allowed for a different perception of others. In this way, drinking enables emotional and embodied encounters in (public) space that are 'separate from seriousness' (Jayne and Valentine, 2016: 75; Stevens, 2007: 41).

\section{Conclusion}

As we noted at the beginning of this article, the affective and embodied experience of drinking for young men has received relatively little attention in the sociological literature on calculated hedonism. In contrast, this study explores 'fun' as an important part of young men's drinking practices. Alcohol is consumed for its pleasurable effects, but pleasure is not only attributed to the effects of intoxication. Rather, pleasure emerges also from the unpredictability - or tension - of play, which includes engagement and competition with other people such as friends and potential sexual partners.

Consistent with calculated hedonism approaches, we found that among these male participants alcohol consumption was bounded by time constraints imposed by employment and other obligations. However, by conceptualising young men's drinking events as play, our analysis provides additional insights into the affective and embodied experiences of such consumption. Play provides time-out-of-time or engagement in 'temporary worlds' (Huizinga, 1949: 29). To quote Huizinga again, play is prized because of the 'meaning it contains, its significance, its expressive value, its spiritual and social associations, in short, as a culture function' (Huizinga, 1949: 27). Our analysis demonstrates that the concept of play can be used to shed light on men's affective engagement in, and embodied experience of, drinking events. By analysing alcohol consumption as part of play, we can incorporate calculated hedonism's focus on the boundedness imposed by time and space, but also locate drinking as part of an event or assemblage. Our analysis also provides a more nuanced way of conceptualising men's alcohol consumption that acknowledges drinking as part of pleasure-seeking beyond neoliberal framings of risk and responsibility. This study therefore contributes to knowledge by exploring the emotionality of young men's drinking practices, and the way in which alcohol is configured in the gendered production of 'play'. Future research might focus more closely on such aspects in 
order to develop a more comprehensive understanding of the affective and embodied dimensions of male drinking.

\section{Acknowledgments}

The research reported in this paper was funded by Australian Research Council Discovery Project

DP110101720. The National Drug Research Institute at Curtin University is supported by funding from the Australian Government under the Substance Misuse Prevention and Service Improvement Grants Fund.

\section{References}

Australian Institute of Health and Welfare. (2014). The National Drug Strategy Household Survey 2013. Canberra: Australian Institute of Health and Welfare.

Barbalet, J. M. (2001). Emotion, Social Theory, and Social Structure: A Macrosociological Approach. Cambridge \& New York: Cambridge University Press.

Bourgois, P. (1999). Theory, Method, and Power in Drug and HIV-Prevention Research: A ParticipantObserver's Critique. Substance Use and Misuse, 34(14), 2155-2172.

Boyatzis, R. (1998). Transforming Qualitative Information. Thousand Oaks: Sage Publications.

Brain, K., Parker, H. and Carnwath, T. (2000). Drinking with Design: Young Drinkers as Psychoactive Consumers. Drugs: Education, Prevention, and Policy, 7(1), 5-20.

Brown, R. and Gregg, M. (2012). The Pedagogy of Regret: Facebook, Binge Drinking and Young Women. Continuum, 26(3), 357-369.

Caillois, R. (2001 [1961]). Man, Play and Games (B. Meyer, Trans.). Urbana: University of Illinois Press.

Crocket, H. (2014). An Ethic of Indulgence? Alcohol, Ultimate Frisbee and Calculated Hedonism. International Review for the Sociology of Sport. Published online, July 30, 2014, doi: $10.1177 / 1012690214543960$.

Duff, C. (2008). The Pleasure in Context. International Journal of Drug Policy, 19(5), 384-392.

Featherstone, M. (1982). The Body in Consumer Culture. Theory, Culture and Society, 1(2), 18-33.

Featherstone, M. (2007). Consumer Culture and Postmodernism. London: Sage. 
Foucault, M. (1988). Technologies of the Self. In L. Martin, H. Gutman and P. Hutton (Eds.), Technologies of the Self: A Seminar with Michel Foucault (pp. 16-49). London: Tavistock.

Fry, M.-L. (2011). Seeking the Pleasure Zone: Understanding Young Adult's Intoxication Culture. Australasian Marketing Journal, 19(1), 65-70.

Giddens, A. (1964). Notes on the Concepts of Play and Leisure. The Sociological Review, 12(1), 73-89.

Goffman, E. (1959). The Presentation of Self in Everyday Life. Garden City: Doubleday.

Griffin, C., Bengry-Howell, A., Hackley, C., Mistral, W. and Szmigin, I. (2009). `Every Time I Do It I Absolutely Annihilate Myself': Loss of (Self-)Consciousness and Loss of Memory in Young People's Drinking Narratives. Sociology, 43(3), 457-476.

Harnett, R., Thom, B., Herring, R. and Kelly, M. (2000). Alcohol in Transition: Towards a Model of Young Men's Drinking Styles. Journal of Youth Studies, 3(1), 61-77.

Harrison, L., Kelly, P., Lindsay, J., Advocat, J. and Hickey, C. (2011). 'I Don't Know Anyone That has Two Drinks a Day': Young People, Alcohol and the Government of Pleasure. Health, Risk and Society, 13(5), 469-486.

Hochschild, A.R. (1979). Emotion Work, Feeling Rules, and Social Structure. American Journal of Sociology, 85(3), 551-575.

Huizinga, J. (1949). Homo Ludens: A Study of the Play-Element in Culture. London: Routledge and Kegan Paul.

Jayne, M., Gibson, C., Waitt, G. and Valentine, G. (2012). Drunken Mobilities: Backpackers, Alcohol, 'Doing Place'. Tourist Studies, 12(3), 211-231.

Jayne, M., Holloway, S. L. and Valentine, G. (2006). Drunk and Disorderly: Alcohol, Urban Life and Public Space. Progress in Human Geography, 30(4), 451-468.

Jayne, M. and Valentine, G. (2016). Alcohol-Related Violence and Disorder: New Critical Perspectives. Progress in Human Geography, 40(1), 67-87.

Jayne, M., Valentine, G. and Holloway, S.L. (2008). Fluid Boundaries—British Binge Drinking and European Civility: Alcohol and the Production and Consumption of Public Space. Space and Polity, 12(1), 81-100. 
Jayne, M., Valentine, G. and Holloway, S. L. (2010). Emotional, Embodied and Affective Geographies of Alcohol, Drinking and Drunkenness. Transactions of the Institute of British Geographers, 35(4), $540-554$.

Katainen, A. and Rolando, S. (2014). Adolescents' Understandings of Binge Drinking in Southern and Northern European Contexts - Cultural Variations of 'Controlled Loss of Control'. Journal of Youth Studies, 18(2), 151-166.

Katz, J. (1988). Seductions of Crime: Moral and Sensual Attractions in Doing Evil. New York: Basic Books.

Keane, H. (2009). Intoxication, Harm and Pleasure: An Analysis of the Australian National Alcohol Strategy. Critical Public Health, 19(2), 135-142.

Lindsay, J. (2006). A Big Night Out in Melbourne: Drinking as an Enactment of Class and Gender. Contemporary Drug Problems, 33(1), 29-61.

Measham, F. (2002). 'Doing Gender' - 'Doing Drugs': Conceptualising the Gendering of Drugs Cultures. Contemporary Drug Problems, 29(2), 335-373.

Measham, F. (2004a). The Decline of Ecstasy, the Rise of 'Binge' Drinking and the Persistence of Pleasure. Probation Journal, 51(4), 309-326.

Measham, F. (2004b). Play Space: Historical and Socio-Cultural Reflections on Drugs, Licensed Leisure Locations, Commercialisation and Control. International Journal Of Drug Policy, 15(5), 337-345.

Measham, F. (2006). The New Policy Mix: Alcohol, Harm Minimisation, and Determined Drunkenness in Contemporary Society. International Journal Of Drug Policy, 17(4), 258-268.

Measham, F. and Brain, K. (2005). 'Binge' Drinking, British Alcohol Policy and the New Culture of Intoxication. Crime, Media, Culture, 1(3), 262-283.

Moore, D. (2010). Beyond Disorder, Danger, Incompetence and Ignorance: Rethinking the Youthful Subject of Alcohol and Other Drug Policy. Contemporary Drug Problems, 37, 475-498.

Mumby, D. K., \& Putnam, L. L. (1992). The Politics of Emotion: A Feminist Reading of Bounded Rationality. The Academy of Management Review, 17(3), 465-486.

Palmer, C. and Thompson, K. (2010). Everyday Risks and Professional Dilemmas: Fieldwork with AlcoholBased (Sporting) Subcultures. Qualitative Research, 10(4), 421-440. 
Parker, H. and Williams, L. (2003). Intoxicated Weekends: Young Adults' Work Hard-Play Hard Lifestyles, Public Health and Public Disorder. Drugs: Education, Prevention, and Policy, 10(4), 345-367.

Payne, G. and Payne, J. (2004). Key Concepts in Social Research. London: Sage.

Roberts, M. (2015). 'A Big Night Out': Young People's Drinking, Social Practice and Spatial Experience in the 'Liminoid' Zones of English Night-Time Cities. Urban Studies, 52(3), 571-588.

Stevens, Q. (2007). The Ludic City: Exploring the Potential of Public Spaces. London: Routledge.

Szmigin, I., Griffin, C., Mistral, W., Bengry-Howell, A., Weale, L. and Hackley, C. (2008). Re-Framing 'Binge Drinking' as Calculated Hedonism: Empirical Evidence from the UK. International Journal of Drug Policy, 19(5), 359-366.

Turner, J.H. (2009). The Sociology of Emotions: Basic Theoretical Arguments. Emotion Review, 1(4), 340354.

Waitt, G., Jessop, L. and Gorman-Murray, A. (2011). 'The Guys in There Just Expect to be Laid': Embodied and Gendered Socio-Spatial Practices of a 'Night Out' in Wollongong, Australia. Gender, Place and Culture, 18(2), 255-275.

Zajdow, G. and MacLean, S. (2014). 'I Just Drink for That Tipsy Stage': Young Adults and Embodied Management of Alcohol Use. Contemporary Drug Problems, 41(4), 522-535. 